\title{
Schistosoma mansoni Vector Snails in Antigua and Montserrat, with Snail-Related Considerations Pertinent to a Declaration of Elimination of Human Schistosomiasis
}

\author{
Martina R. Laidemitt, ${ }^{1 *} \dagger$ Sarah K. Buddenborg, ${ }^{2} \dagger$ Lowell L. Lewis, ${ }^{3}$ Lionel E. Michael, ${ }^{4}$ Maria J. Sanchez, ${ }^{5}$ Reynold Hewitt, ${ }^{6}$ \\ and Eric S. Loker ${ }^{1}$ \\ ${ }^{1}$ Center for Evolutionary and Theoretical Immunology, Parasite Division, Museum of Southwestern Biology, Department of Biology, University of \\ New Mexico, Albuquerque, New Mexico; ${ }^{2}$ Wellcome Sanger Institute, Cambridgeshire, United Kingdom; ${ }^{3}$ Government of Montserrat, Brades, \\ Montserrat; ${ }^{4}$ Environmental Health Division, Ministry of Health and Social Development, Road Town, Tortola, British Virgin Islands; ${ }^{5}$ Pan American \\ Health Organization, Washington, District of Columbia; ${ }^{6}$ One Health Centerfor Zoonoses and Tropical Veterinary Medicine, Ross University School \\ of Veterinary Medicine, Basseterre, Saint Kitts and Nevis
}

\begin{abstract}
Investigations leading to a WHO-validated declaration of elimination of schistosomiasis transmission are contemplated for several countries, including Caribbean island nations. With assistance from the Pan American Health Organization, we undertook freshwater snail surveys in two such nations, Antigua and Barbuda, and Montserrat in September and October 2017. Historically, the transmission of Schistosoma mansoni supported by the Neotropical vector snail Biomphalaria glabrata occurred in both countries. Transmission on the islands is thought to have been interrupted by the treatment of infected people, improved sanitation, introduction of competitor snails, and on Montserrat with the eruption of the Soufrière volcano which decimated known B. glabrata habitats. Guided by the available literature and local expertise, we found Biomphalaria snails in seven of 15 and one of 14 localities on Antigua and Montserrat, respectively, most of which were identified anatomically and molecularly as Biomphalaria kuhniana. Two localities on Antigua harbored B. glabrata, but no schistosome infections in snails were found. For snail-related aspects of validation of elimination, there are needs to undertake basic local training in medical malacology, be guided by historical literature and recent human schistosomiasis surveys, improve and validate sampling protocols for aquatic habitats, enlist local expertise to efficiently find potential transmission sites, use both anatomical and molecular identifications of schistosomes or putative vector snail species found, if possible determine the susceptibility of recovered Biomphalaria spp. to S. mansoni, publish survey results, and provide museum vouchers of collected snails and parasites as part of the historical record.
\end{abstract}

\section{INTRODUCTION}

In 2017, the World Health Assembly adopted WHA70.16, which proposed reinforcing snail control as part of the strategy to eliminate human schistosomiasis as a public health problem. ${ }^{1}$ This is a daunting task because as estimated by the WHO, schistosomiasis transmission occurs in 78 countries, and at least 229 million people required preventive treatment in $2018 .^{1}$ An estimated 1.6 million individuals with intestinal schistosomiasis caused by Schistosoma mansoni reside in the Americas. ${ }^{1}$ Although schistosomiasis transmission persists in Brazil, Suriname, and Venezuela, ${ }^{1,2}$ its current status on several Caribbean islands formerly known to be endemic is currently not well understood. ${ }^{3,4}$ Some nations in the Caribbean are considered to have interrupted $S$. mansoni transmission and have been taken off the list of countries with endemic transmission, including Antigua and Barbuda, the Dominican Republic, Guadeloupe, Martinique, Puerto Rico, and Montserrat. ${ }^{3,5}$ However, these claims require further verification, including whether the major $S$. mansoni snail vector in the region, Biomphalaria glabrata, is still present. Although schistosomiasis can surely be eliminated in locations where vector snail species persist, such as in Japan, continuing presence or not of susceptible vector species in a country targeted for elimination obviously remains a pertinent consideration. Biomphalaria glabrata was once known from at least 12 Caribbean islands, but its continuing presence on most has been questioned. ${ }^{6,7}$ Ecological changes, particularly the introduction of exotic competitor freshwater snails such as

\footnotetext{
*Address correspondence to Martina R. Laidemitt, University of New Mexico, 1 University of New Mexico, Department of Biology, MSC03 2020, Albuquerque, NM 87131. E-mail: mlaidemitt@unm.edu †These authors contributed equally to this work.
}

Melanoides tuberculata and Thiara granifera, are believed to be responsible for sharp declines in $B$. glabrata abundance. ${ }^{7}$ Additional species of Biomphalaria are also known from the Caribbean islands, ${ }^{6,8}$ and their status as possible hosts for S. mansoni there requires further study.

As part of an early stage in the consideration of declaration of elimination of schistosomiasis transmission in the Caribbean, the Pan American Health Organization (PAHO) supported an exploratory survey of two islands, Antigua and Montserrat, with respect to the status of schistosome vector snails currently present. Barbuda was not sampled as Hurricane Irma decimated much of the island in September and October 2017. Schistosoma mansoni was first established in Antigua and Barbuda and Montserrat following the influx of people of African descent into the Neotropics in the fifteenth century and was efficiently transmitted by indigenous populations of $B$. glabrata. ${ }^{9,10}$ Studies from Antigua in the 1920s found approximately $18 \%$ of people were infected with S. mansoni in St. John Parish and a 1930 s survey found $60 \%$ of people living in St. John Parish near Bendel's stream and Body Pond were infected. ${ }^{4,9,11}$ These locations were sites where B. glabrata was also found. ${ }^{9}$ The prevalence of S. mansoni in Antigua then declined over the course of the twentieth century. By the 1980s, the prevalence of S. mansoni declined to less than $1 \%$, likely in response to the introduction of $T$. granifera and infrastructure improvements. ${ }^{9,12,13}$

Surveys conducted in the late 1970s and 1980s on Montserrat found $10-14 \%$ of people were infected with S. mansoni in villages on the island's windward eastern side ${ }^{10,14,15}$ where B. glabrata habitats were also found. ${ }^{9}$ These villages were Trants, Farms, Bethel, Bramble, and Tuitts. ${ }^{4,14}$ In 1995, the Soufrière Hills volcano that dominates the island's landscape erupted and left the southern half of the island devastated. ${ }^{16}$ 
The habitats where $B$. glabrata were present on the eastern slopes of the volcano were likely destroyed by pyroclastic flows. The eruption of the volcano, in combination with the introduction of competitor snails such as $M$. tuberculata, is believed to have eliminated $B$. glabrata from the island. ${ }^{15,17}$ Although both Antigua and Montserrat are considered to no longer have endemic transmission of S. mansoni, parasitological confirmation is lacking. In addition, there is an absence of recent published surveys of freshwater snails in either country.

Eventual confirmation of the elimination of human schistosomiasis in the Caribbean is of importance in several regards. It would mark the end of an underappreciated health threat to local populations, especially children. It would also preclude infection risks for the millions of people who visit the Caribbean each year. Recent experiences in Corsica show how tourist populations can be at risk of schistosomiasis ${ }^{18}$ and highlight the need for surveillance. Also, efforts on the islands of the Caribbean can help to establish protocols and procedures that might prove valuable when elimination and subsequent validation efforts are eventually undertaken in mainland countries.

In September and October 2017, we visited Antigua and Montserrat with the aim of first providing workers from the respective ministries of health with basic malacology training, and then conducting snail surveys looking for living Biomphalaria snails in selected localities. The basic training was designed to encourage and facilitate future additional searches. In this study, the surveys are reported and observations and future strategies and needs relevant to malacological aspects of the eventual declaration of elimination of schistosomiasis are outlined. The focus of this article was on snail-related aspects of validation of the elimination process, with the realization that separate efforts to document infection or transmission in resident human, or domestic or wild mammal, populations will require expertise from different teams of investigators.

\section{MATERIALS AND METHODS}

Sampling. We collected snails from 15 different freshwater localities in Antigua and 14 localities from Montserrat between September and October 2017 (Table 1). We did not visit Barbuda because Hurricane Irma had recently inflicted heavy damage, causing most people on the island to evacuate. At each locality, we recorded GPS coordinates, habitat type, altitude, distinctive features, and the presence of people and/ or animals, and collected freshwater snails (Figure 1). Aquatic snails were collected along the water's edge using kitchen sieves to sweep aquatic vegetation or a long-handled metal net to scoop along the substrate, rocks, and aquatic vegetation in deeper water. Snails were also picked off submerged rocks, plants, sticks, or debris using forceps. Collection at each locality lasted between 30 minutes and 1 hour. The time spent at each site varied because of the size of the habitat and to ensure thorough collection measures were completed. After collection, debris was removed from snail shells with a Kimwipe $^{\mathrm{TM}}$ (Kimberly-Clark Corp., Irvine, TX) and were rinsed with clean water. Snails were placed individually into 12-well tissue culture plates in $3 \mathrm{~mL}$ of water. The tissue culture plates were placed in ambient light and left overnight to induce shedding of cercariae as some cercariae may shed at night. The plates were then screened for cercariae using a dissecting scope. Keys were used for the identification of snails ${ }^{6}$ and their trematodes. ${ }^{19}$ Snails and cercariae were fixed in $95 \%$ ethanol for later molecular analysis. Some snails were relaxed using menthol crystals and, following the procedures of Pan, ${ }^{20}$ were removed from their shells and fixed in Railliet-Henry solution to facilitate dissections and anatomical observations.

Molecular characterization of Biomphalaria and closely related snails. Partial sequences of the $16 \mathrm{~S}$ rRNA and internal transcribed spacers one and two (ITS1 and ITS2) were amplified by PCR. Snail genomic DNA was extracted from one or two specimens from each locality ( 16 specimens in total) using the ENZA Mollusc Kit (Omega Bio-Tek, Norcross, CA). The primers used in this study were used to compare and differentiate Biomphalaria sequences obtained from GenBank and collected in this study (Figures 1 and 2). The internal transcribed spacer was amplified using ITS1-S, 5' CCATGAACGAGGAATTCCCAG 3'; BD2, 5' TATGCTTAAATTCAGCGGGT 3'; and ITS2.2, 5' CCTGGTTAGTTTCTITTCCTCCGC3' primers. ${ }^{21}$ The $16 \mathrm{~S}$ region was amplified using $16 \mathrm{Sar}$, 5' CGCCTGTITATCAAAAACAT 3' and 16Sbr, 5' CCGGTCTGAACTCAGATCACGT3' primers. ${ }^{22}$ The volume of each PCR was $25 \mu \mathrm{L}$, with $1 \mu \mathrm{L}$ of $100 \mathrm{ng}$ of DNA, $0.8 \mathrm{mM} / \mathrm{L}$ of deoxynucleotides, $2.5 \mathrm{mM} / \mathrm{L}$ of $\mathrm{MgCl}_{2}, 0.2$ units of Ex Taq DNA (Clontech, Mountain View, CA), and $0.4 \mu \mathrm{M} / \mathrm{L}$ of each primer. PCR cycles for both genes followed by study by Palumbi. ${ }^{22}$

PCR fragments were separated by agarose gel electrophoresis and visualized with $0.5 \%$ GelRed $^{\mathrm{TM}}$ nucleic acid gel stain (Biotium Inc., Hayward, CA) and were purified using the ExoSapIT (Applied Biosystems, Foster City, CA). Both strands were sequenced using an Applied Biosystems 3130 automated sequencer and BigDye Terminator Cycle Sequencing Kit version 3.1 (Applied Biosystems). DNA sequences were verified by aligning reads from the $5^{\prime}$ and 3 ' directions using Sequencher 5.0 and manually corrected for ambiguous base calls (Gene Codes, Ann Arbor, MI). Approximately 1,149 bases were generated from ITSs and 470 bases from the $16 \mathrm{~S}$ gene. Sequences were aligned using CLUSTAL W, and the best fit model of substitution for both genes was modeled in Molecular Evolutionary Genetics Analysis7. ${ }^{23}$ Phylogenetic analyses using maximum likelihood (ML) included our 13 samples along with 43 sequences from National Center for Biotechnology Information-GenBank for ITSs and 60 for 16S. A total of 1,277 positions were used for ITS alignment and 413 positions for the $16 \mathrm{~S}$ alignments. Heuristic searchers were used for $\mathrm{ML}$ analyses, and 1,000 bootstrap replicates were run for each dataset. Sequences generated in this study were submitted to GenBank. Our specimens were also deposited as vouchers in the Museum of Southwestern Biology (Table 1).

Molecular detection for prepatent (not shedding) S. mansoni infections from the previously extracted Biomphalaria was also performed. We tested if we could amplify S. mansoni or Schistosoma rodhaini DNA using the nicotinamide adenine dinucleotide dehydrogenase subunit 5 (ND5) PCR assay described by Lu et al. ${ }^{24}$ This is a sensitive assay ( $>0.1 \mathrm{fg}$ DNA) and differentiates Schistosoma species either by band size or absence/presence. We followed the same PCR gel detection protocol as described by Lu et al. ${ }^{24}$

\section{RESULTS}

Antigua. Among the 15 localities sampled (Figure 3A), we collected 971 freshwater snails representing at least 12 different species, all of which were isolated and examined for 


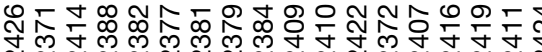

สิ

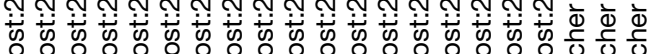

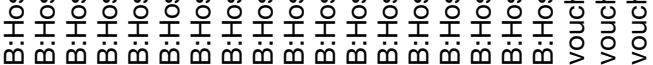

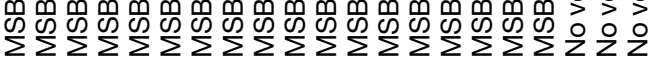

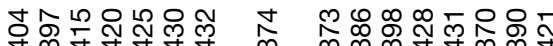

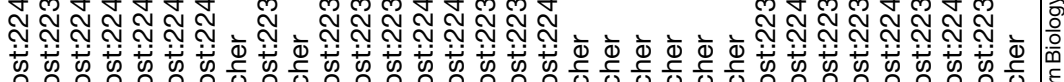

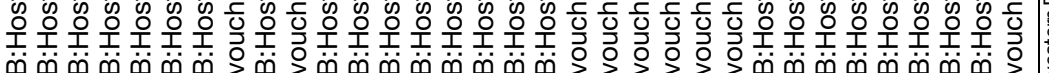

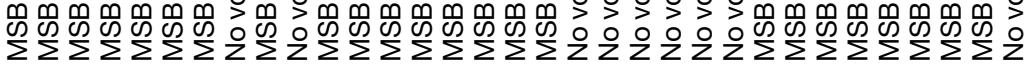

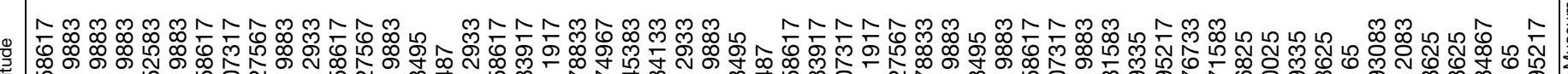

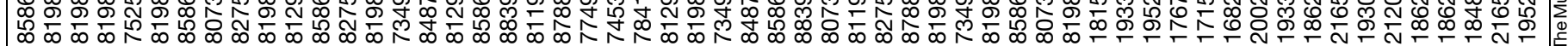
फ़

W

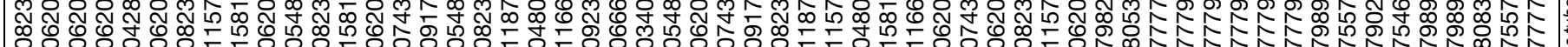

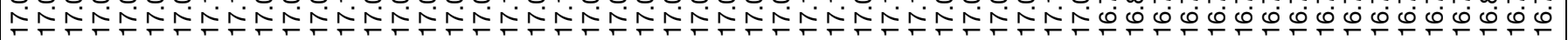

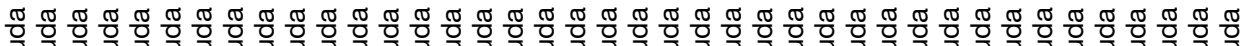

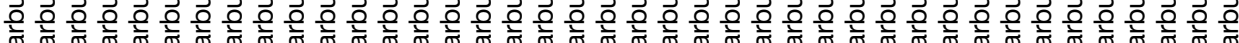

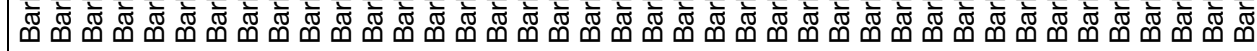

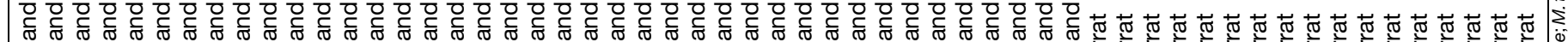

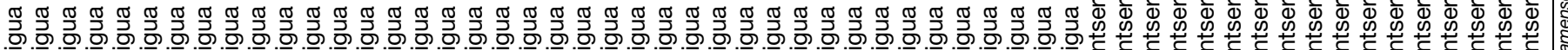

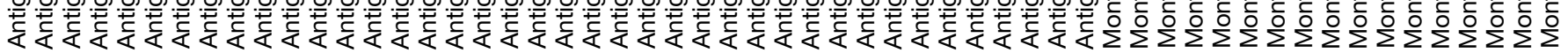

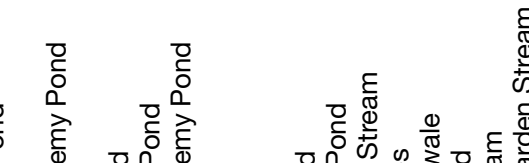

密

कृ

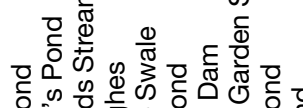

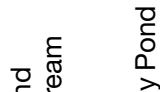

둥

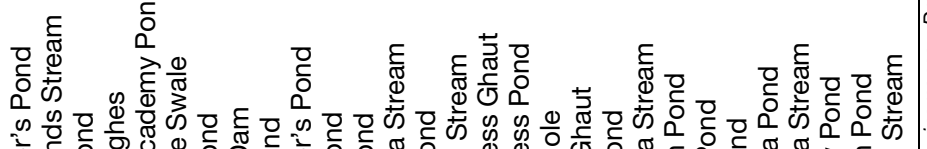
$\begin{array}{llll} & \\ 0\end{array}$

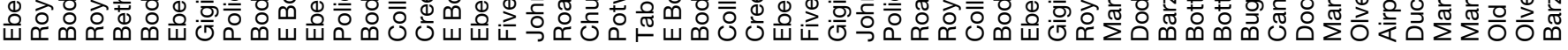

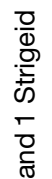

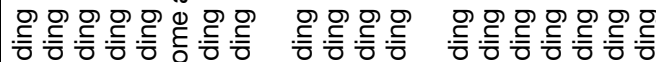

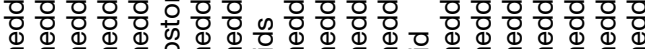

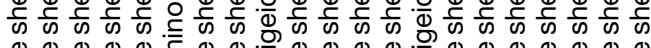

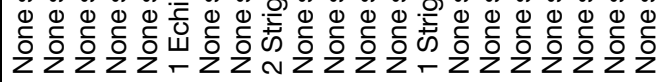

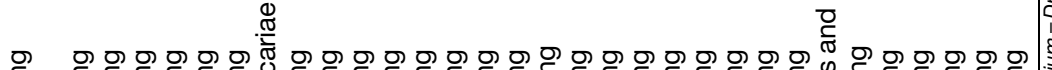

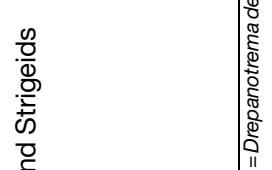

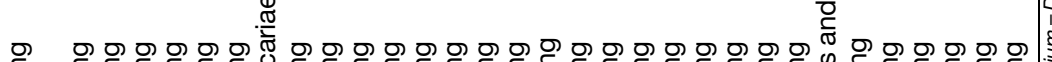
ThEF ชับ

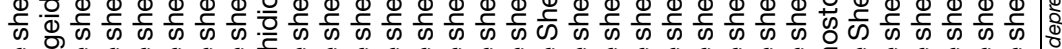
..............................

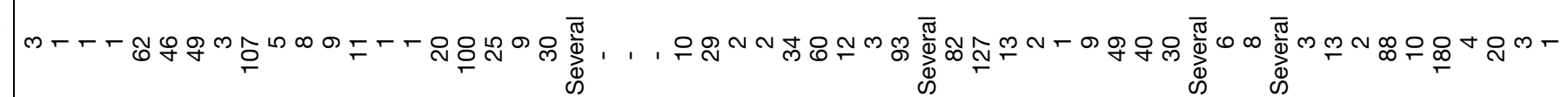

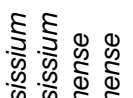

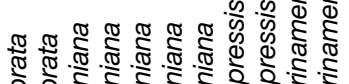

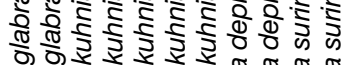

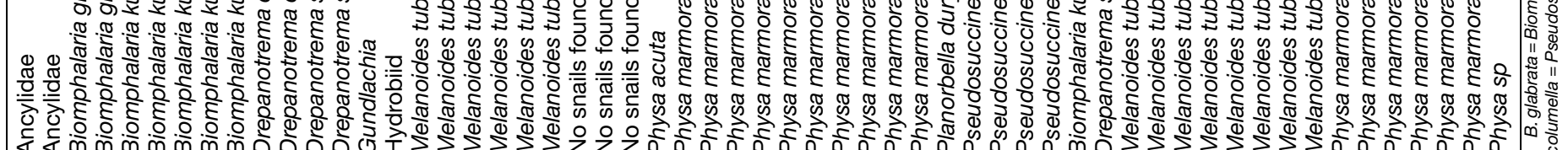

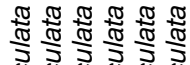

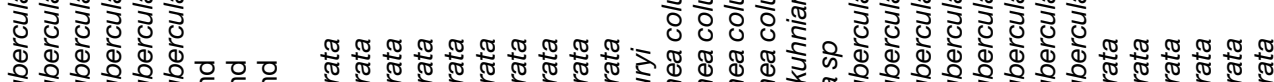



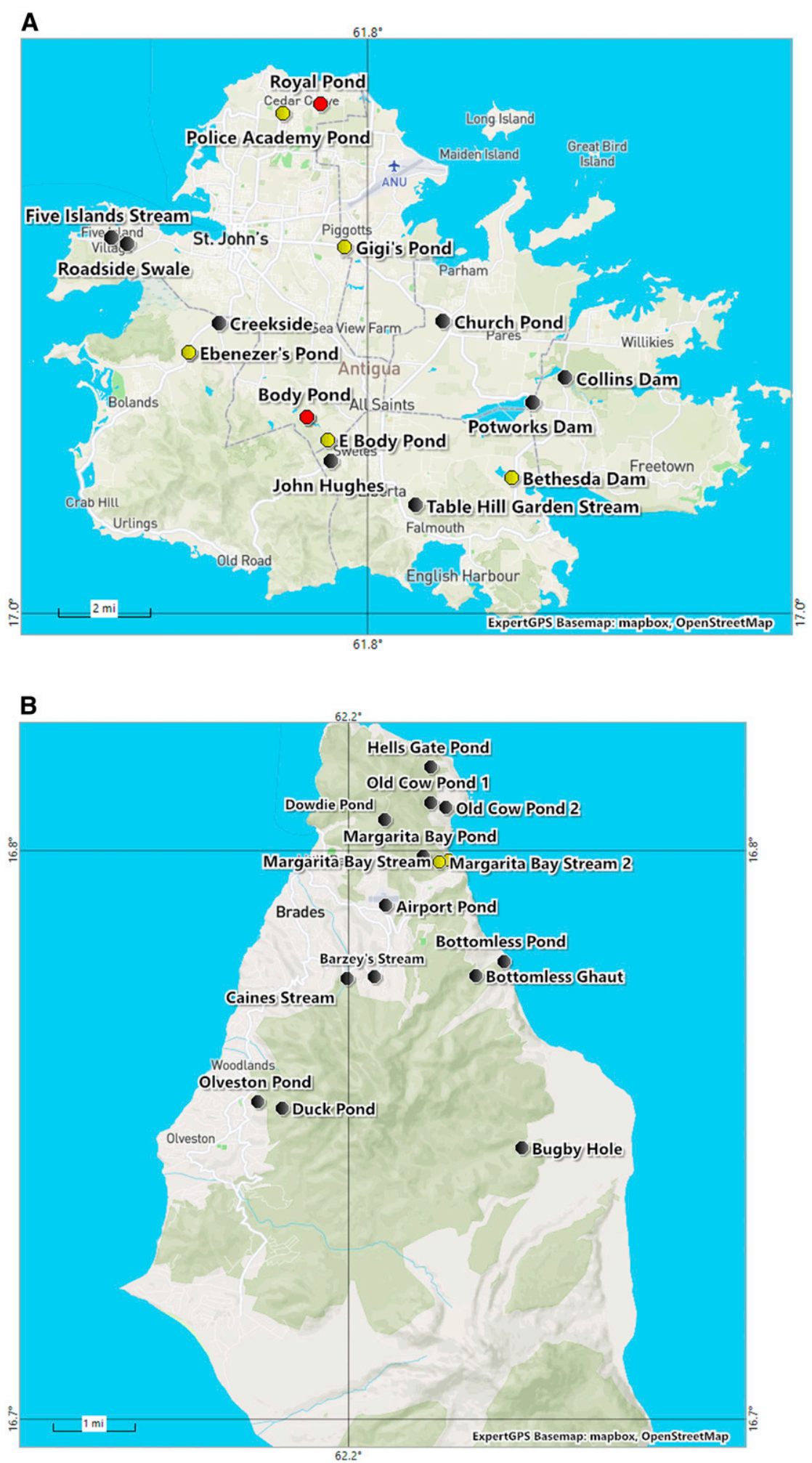

FIGURE 1. ExpertGPS basemaps of Antigua (A) and Montserrat (B), and the localities we sampled for aquatic snails. Highlighted with a yellow circle are localities where Biomphalaria kuhniana were collected, and highlighted in a red circle are localities where Biomphalaria glabrata were collected. Localities with black circles are non-Biomphalaria sites. This figure appears in color at www.ajtmh.org.

trematode cercariae. All snail and cercariae samples are reported in Table 1. We found Biomphalaria (269) in seven localities. Identification of the snails was confirmed by morphological features, dissections, and by sequence data for ITSs (GenBank accession numbers MT753102MT753117) and 16S marker genes (GenBank accession numbers MT753134-MT753149), which showed Biomphalaria kuhniana was present in six/seven localities and 


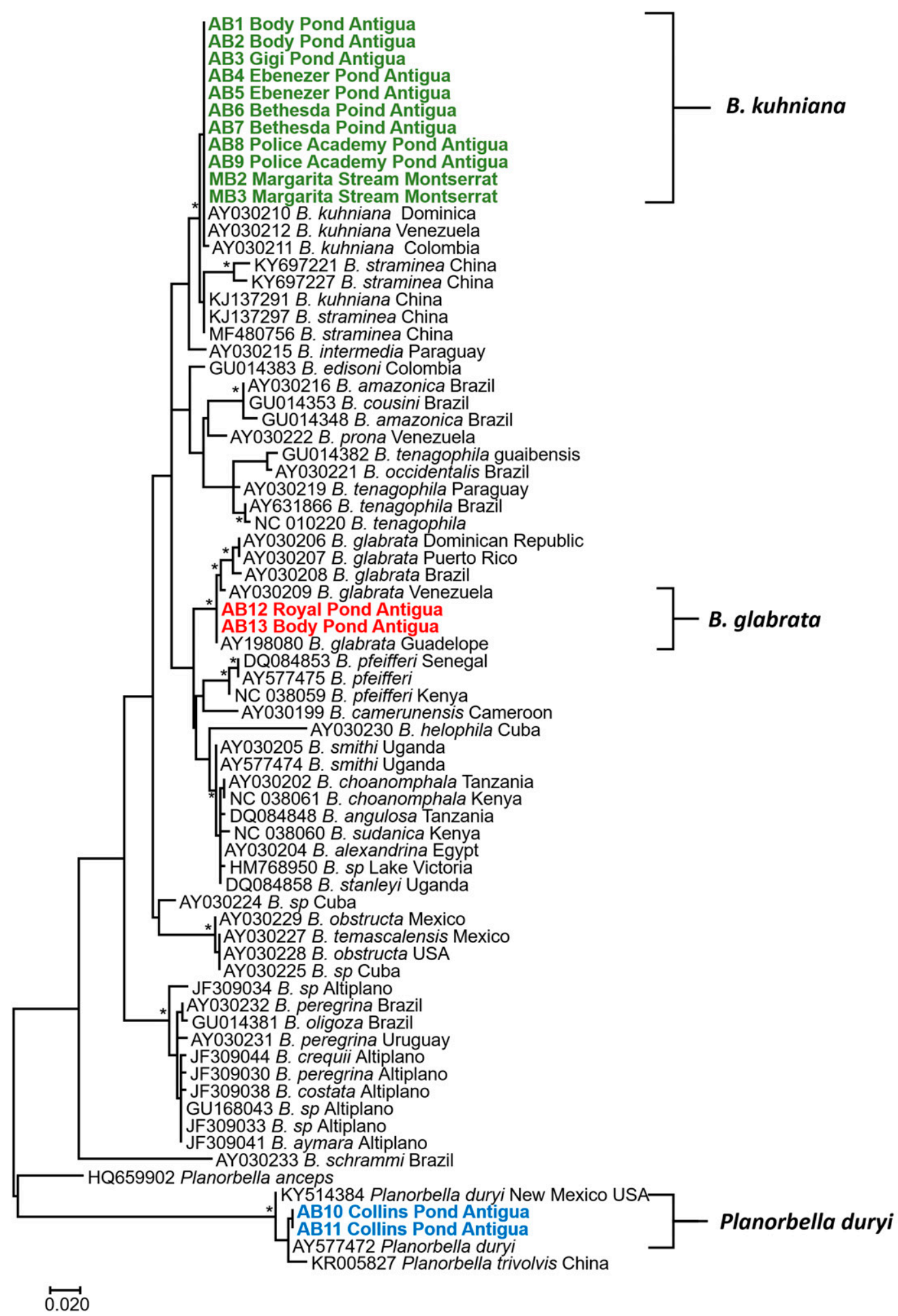

FIGURE 2. Phylogenetic tree based on 461 positions of the $16 \mathrm{~S}$ rDNA gene. A total of 1,000 bootstraps were run, and model GTR + I + G was selected via model selection. * denotes nodes greater than $90 \%$. Specimens obtained from Antigua and Montserrat are shown in bold and colored according to different species. This figure appears in color at www.ajtmh.org.

B. glabrata was present in two/seven localities (Figures 1 and 2). One snail conchologically resembling $B$. glabrata was collected from Royal Pond, and its identity was confirmed based on sequence data. A snail too small for specific morphological identification was collected from Body Pond and was confirmed by sequence data to be $B$. glabrata. All other Biomphalaria collected had shell anatomy and size, dissected genitalia including numbers of prostatic diverticuli, 


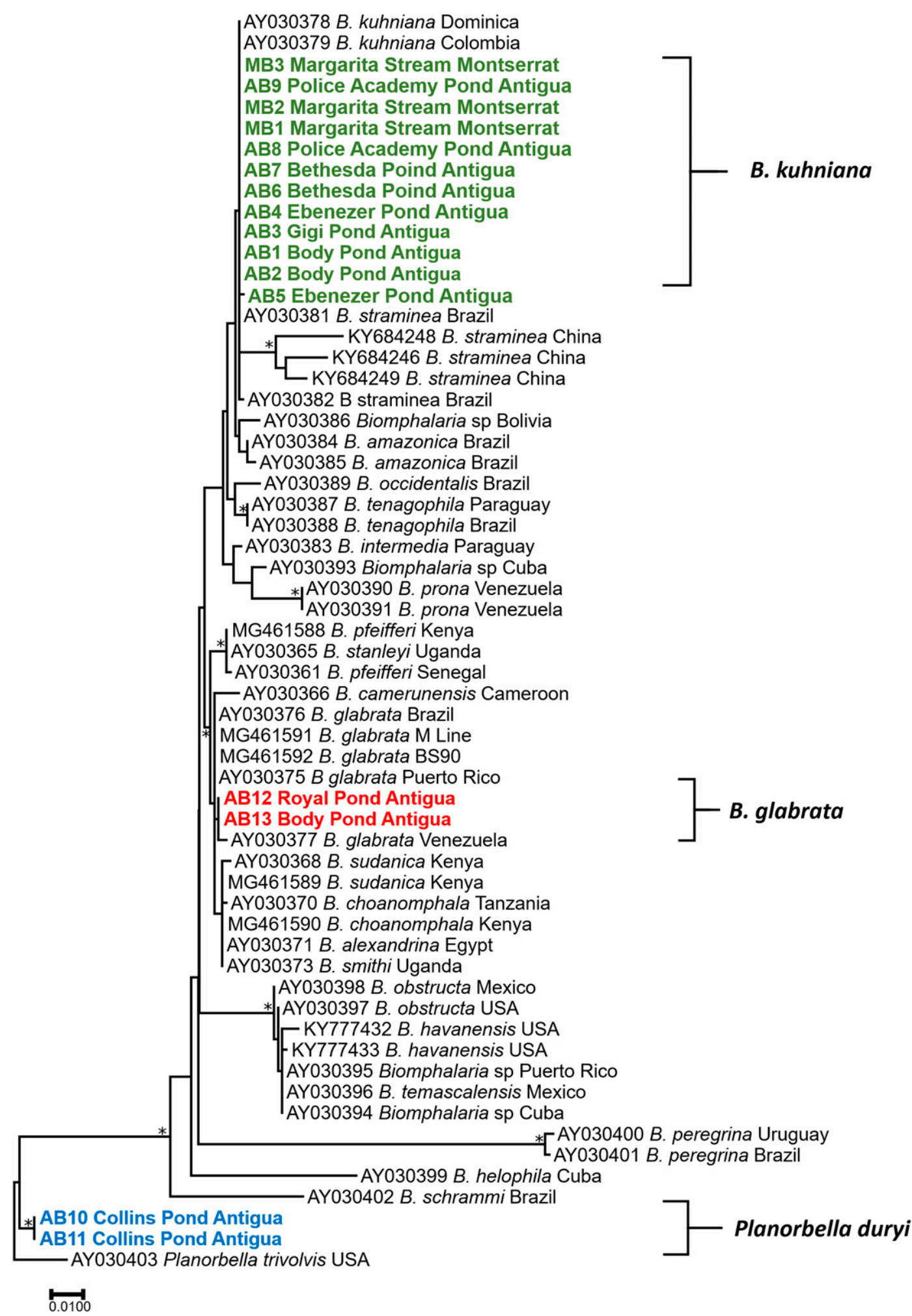

FIGURE 3. Phylogenetic tree based on 964 positions of partial 18S, ITS1, 5.8S, ITS2, and 28S genes. A total of 1,000 bootstraps were run, and model GTR + I + G was selected via model selection. ${ }^{*}$ denotes nodes greater than $90 \%$. Specimens obtained from Antigua and Montserrat are shown in bold and colored according to different species. ITSs = internal transcribed spacers. This figure appears in color at www.ajtmh.org.

and sequence data for the two marker genes consistent with B. kuhniana. ${ }^{6,21}$ No Biomphalaria were found to be shedding schistosome cercariae, nor were they positive for S. mansoni as determined from the ND5 PCR assay. Two of $46 \mathrm{~B}$. kuhniana from Body Pond were positive for digenetic trematode infections, one an echinostome and another a strigeid, and two of 107 B. kuhniana from Police Academy Pond were positive for strigeid infections. No other trematode infections were found 
among the Antiguan Biomphalaria snails we sampled. A dense population of Planorbella duryi was found in Collins Pond and is noteworthy because snails of this species can be readily confused with B. glabrata if dissections or sequence data are not used to differentiate them.

Melanoides tuberculata were collected from 6/15 sites on Antigua. None of the $M$. tuberculata were shedding trematodes. Physa acuta was collected from one locality, and Physa marmorata was collected at 10 different localities, and a few were positive for either strigeid or xiphidiocercaria infections. Pseudosuccinea columella, a known snail host for Fasciola hepatica in $\mathrm{Cuba}^{25}$ was collected at four different localities, and none were shedding trematodes.

Montserrat. We sampled 14 different snail localities on Montserrat (Figure 3B) and from them collected 457 freshwater snails representing at least five different species, all of which were isolated and screened for trematode cercariae. We found 49 Biomphalaria in only one locality, Margarita stream. Sequence data for these snails confirmed their identification as $B$. kuhniana (Figures 1 and 2). Shell anatomy and size, and dissected genitalia including numbers of prostatic diverticuli were all consistent with $B$. kuhniana. ${ }^{6}$ None of the $B$. kuhniana released cercariae of any kind, including schistosomes. None were positive for S. mansoni using the ND5 PCR assay.

Of the 14 Montserrat locations sampled, M. tuberculata were found in eight localities, including Margarita Stream. Physa marmorata was also collected at 6/14 localities sampled and was the only snail species we found harboring trematode infections (echinostomes and strigeids) on the island. We did not collect any $P$. columella on Montserrat. No schistosome parasites of any kind were found among the snails we surveyed on either island.

\section{DISCUSSION}

An important part of the process for verification of the elimination of human schistosomiasis is to gather data on the presence, distribution, and species composition of known or suspected schistosome vector snails and the schistosomes or other trematodes they may harbor. Although schistosomiasis elimination can be achieved even if appropriate snail vector species are still present, the status of vector populations is clearly germane to elimination and its prospects for long-term success. Biomphalaria snails were found in $7 / 15$ localities sampled on Antigua and 1/14 localities sampled on Montserrat, most of which were B. kuhniana. To our knowledge, $B$. kuhniana has not been reported in the literature as a naturally infected vector of $S$. mansoni from any location. ${ }^{26}$ However, one article reported Biomphalaria straminea as naturally infected with $S$. mansoni in Venezuela, ${ }^{27}$ but these may have been $B$. kuhniana. ${ }^{21}$ Also, Paraense noted finding naturally infected $B$. kuhniana from Martinique (Pointier, personal communication), but this has not been verified. Experimental exposures of $B$. kuhniana to $S$. mansoni report a lack of compatibility. ${ }^{28,29}$

At the loci sequenced and analyzed, we found limited genetic variation between Antiguan and Montserratian $B$. kuhniana and Brazilian B. straminea (16S uncorrected $P$ distance value, $P=0.0515)$, the latter a known $S$. mansoni vector. ${ }^{21,30,31}$ Morphologically, there are also few well-defined features to distinguish these two taxa. Further experimental exposures are also clearly warranted because $B$. kuhniana has been reported widely from both the South American mainland and several islands of the Lesser Antilles, ${ }^{6}$ and its susceptibility to $S$. mansoni might vary with location or potentially be assisted by coinfections with other trematode species.

Although we did not find Biomphalaria infected with schistosomes, we found at least two different species of nonschistosome trematodes transmitted through $B$. kuhniana on Antigua. One is a strigeid of the genus Apharyngostrigea and the second an echinostome that closely resembles Petasiger caribbensis reported by Nassi ${ }^{32}$ from B. glabrata from Guadeloupe. Although $P$. caribbensis was first described from $B$. glabrata, it is shown here to be transmitted by $B$. kuhniana, which serves as a reminder that $S$. mansoni too could have a similar propensity to infect multiple Biomphalaria species.

We found two localities on Antigua that harbored B. glabrata, but we did not collect any $B$. glabrata on Montserrat, supporting reports ${ }^{33}$ that the eruption of the Soufrière Hills volcano eliminated its known habitats on the island. ${ }^{33}$ However, ours was a one-time collection trip, and we were only able to get to one site in the current exclusion zone, Bugby Hole, where $B$. glabrata was formerly found. Further sampling is recommended because $B$. glabrata occurs on Antigua only $54 \mathrm{~km}$ away, and introductions and extinctions are relatively common events on islands. People or birds may inadvertently transport this snail species to Montserrat as has happened with the exotic snail $M$. tuberculata, which has been known since at least 2001 on Montserrat. ${ }^{17}$

The widespread establishment of $M$. tuberculata on the islands ( $48 \%$ of localities surveyed) may preclude reintroductions of $B$. glabrata as it has been shown to be a potent competitor with B. glabrata on other Caribbean islands. ${ }^{7,34}$ Apart from one locality, Ebenezer's Pond, we did not find M. tuberculata to coexist with Biomphalaria snails. Physa marmorata and $P$. duryi may also have the potential to displace $B$. glabrata or prevent its reestablishment because of their competitive ability. ${ }^{35-37}$ If populations of $B$. glabrata persist or are newly found on either island, then a difficult decision may need to be made by local public health and biodiversity experts. From the public health point of view, $B$. glabrata is an excellent vector for $S$. mansoni, but from a conservationist's perspective, especially if $S$. mansoni is no longer present on the island, $B$. glabrata might be considered an endangered native species. Furthermore, if $B$. glabrata was deliberately rendered extinct on the islands, particular species of digenetic trematodes (other than S. mansoni) that depend on B. glabrata might suffer co-extinction, at least locally, unless they can infect other related species such as $B$. kuhniana. There are at least seven different species (excluding $S$. mansoni) of trematodes that are known to use $B$. glabrata as an intermediate host in the Caribbean region. ${ }^{32,38,39}$ Our comments should not be construed to mean elimination of snail vectors is a requirement for the elimination of schistosomiasis; indeed, preserving biodiversity like snails where possible should be encouraged.

Our survey prompted us to consider more broadly the needs of formal programs for declaration of elimination of schistosomiasis. In our view, such programs must include an accounting of the status of the snail side of the schistosome life cycle. It is tempting to conclude that if schistosome parasites are not found in the human population and are no longer a public health threat, then schistosomiasis is effectively eliminated. However, as the recent situation on the island of 
Corsica reminds us, schistosomes often have wild or domestic mammalian reservoir hosts that can serve as a source of infection for snails, leading to surprising reemergence of infections in humans. ${ }^{18}$ There is certainly a precedent for something similar to occur on the Caribbean islands as a focus of rodent-transmitted $S$. mansoni persisted for years in Guadeloupe after it ceased to be a human public health concern. $^{27,40}$

As to whether vector snail species (or the schistosomes they may harbor) are actually present on the islands, this relates to a significant general problem for all elimination declarations. Such efforts are bedeviled by the fact that the hoped-for goal is to "find nothing," raising the general question of "when is enough surveying and sampling enough?" This issue certainly applies to aspects of schistosomiasis occurring in the water. How then to proceed?

Resources for such endeavors will be limited, and sampling efforts will have to be adjusted depending on available budgets and the size of the country and number of localities requiring assessment. An important early step is to engage locals, educate them about the elimination verification process, and enlist their help in finding snail habitats. During our trip to Antigua and Montserrat, we were surprised about how many people knew of the purpose of our visit. On Montserrat, this was thanks to a brief interview session we held with the local radio station. Crowdsourcing initiatives involving cell phones and pictures of the relevant snails offer promise, but care is required as the process could be corrupted by expectation for rewards for finding the "right" snail species. Repeated visits to at least some and preferably all freshwater habitats are in order because the situation in them can change with season, recent rainfall, droughts, or modifications whether natural, like a volcanic eruption, or human mediated. Repeated visits may need to be guided by known hotspots of schistosome transmission identified from past studies. Certainly, habitats surrounding any villages known to have recently reported infected or seropositive persons or known to have proven populations of vectors like $B$. glabrata would be of interest. Studies like the recent serological survey in St. Lucia to detect lingering $S$. mansoni transmission can also provide valuable guidance for snail survey teams. ${ }^{41}$ If any snails were found to be infected with $S$. mansoni, then more concerted searching for other nearby pockets of infected snails and additional testing of local residents for evidence of infection would be warranted. It would also be useful to examine infected snails with respect to the timing of release of cercariae, as one indication of whether transmission is mediated by humans or possibly rodents. ${ }^{42}$ Release of cercariae at midday would be suggestive of a human-based transmission cycle, but biasing of cercarial release to the evening or early morning hours would be more suggestive transmission was being mediated by rodents. Even in the latter case, the potential for human infection would exist.

Sampling should include traditional snail isolation and shedding methods. With some training, this can ensure broad coverage of many snails. If possible, all collected snails should be held in aquaria and re-shed for cercariae after 2 weeks to determine if any snails may have had prepatent infections at the time of initial collection. This latter aspect has the disadvantage that snail culturing facilities may not be available, and some snails will die during the holding period. Alternatively, molecular xenomonitoring of snails for S. mansoni infection can be used, ${ }^{24,43}$ but some caution is required as this approach requires specialized equipment and reagents, requires validation for sensitivity and specificity of detection of S. mansoni, and may limit the number of snails that can be sampled, a disadvantage if snail populations are large. Pooling snails may help overcome these obstacles but are bound to reduce sensitivity of detection. Relative to elimination considerations, vector snail identifications should be based on both anatomical and molecular criteria. Such specimens have historical significance and should be deposited in museums, allowing ready access to the specimens for future reference and verification.

Availability and implementation of inexpensive alternative sampling strategies permitting wider or more frequent coverage would be a most welcome addition. Environmental DNA (eDNA) methods particularly offer promise for detecting the presence of either vector snails or schistosomes in water samples. ${ }^{44-46}$ Environmental DNA offers the advantages that signals in water samples are integrated across time and space permitting broader coverage, and specific identifications based on DNA sequences recovered can be acquired if desired. In our view, increased use of eDNA approaches is an important goal for future surveys. Most eDNA samples recovered will likely be negative, and well-chosen positive and negative controls will be critical to validate the process. Primer use will also need careful attention because other trematodes can co-occur and may result in false positives for S. mansoni without further verification via sequencing. Current eDNA procedures have not yet been validated across a broad range of transmission conditions, and because of the presumed rarity of $S$. mansoni in the Caribbean, this test environment will offer distinct challenges. Consequently, newer survey techniques are welcomed and encouraged but should be validated, in part by assessing their results alongside traditional specimen-based approaches involving collection, isolation, and shedding techniques followed by molecular identification as needed.

It is possible that repeated searches fail to recover any potential vector species, in which case the likelihood of indigenous transmission would be zero. If suspected vector species are found and their identifications confirmed, it would be helpful to know if they are compatible with local strains of $S$. mansoni. Such exposures need to be undertaken carefully under circumstances that preclude any possibility of S. mansoni reintroductions to the islands. Difficulties in obtaining necessary collection, exportation, and importation permits currently pose substantial hurdles to such endeavors, and assistance by the PAHO or WHO in helping secure such approvals would be very helpful.

Last, we must realize that nothing lasts forever, including declarations of elimination. Biological change is pervasiveintroductions and reintroductions of snails including B. glabrata or other schistosome vectors, and of the schistosomes themselves, are always possible-especially on tropical islands. Local Biomphalaria species like B. glabrata that have been affected by introductions of competitor snails may be gone for good or might adapt and rebound. The backdrop of a rapidly changing climate is likely to have impacts we cannot presently foresee, which could favor or disfavor schistosomiasis transmission in novel ways. Nonetheless, efforts to certify elimination of schistosomiasis for the Caribbean nations are important because they can help us mark tangible progress in 
eliminating one of the most recalcitrant of all neglected tropical diseases and because they can be a testing ground for elimination declarations lying ahead in other nations.

\section{Received June 3, 2020. Accepted for publication July 27, 2020.}

Published online September 8, 2020.

Acknowledgments: We thank the principal environmental health officer of Montserrat, Gareth Stanley, and our field guide James (Scriber) Daley. We also thank W. Evan Secor for his encouragement and for facilitating communications pertaining to our trip and the Montserrat director of environment who approved the collection and exportation of the museum samples. We also thank the Antigua environment director for export approval.

Note: The Pan American Health Organization holds the copyright to this article and has granted the publisher permission for the reproduction of this article.

Financial support: The survey for this study was supported by the Pan American Health Organization (PAHO), and the National Institute of Health (NIH) (Grant R37Al101438) provided logistical support. Technical assistance at the University of New Mexico Molecular Biology Facility was supported by the National Institute of General Medical Sciences of the National Institutes of Health under Award number P30GM110907.

Disclaimer: The content of this article is solely the responsibility of the authors and does not necessarily represent the official views of the National Institutes of Health.

Authors' addresses: Martina R. Laidemitt and Eric S. Loker, Parasitology Division, Department of Biology, Center for Evolutionary and Theoretical Immunology, Museum of Southwestern Biology, University of New Mexico, Albuquerque, NM, E-mails: mlaidemitt@unm.edu and esloker@unm.edu. Sarah K. Buddenborg, Wellcome Sanger Institute, Cambridgeshire, United Kingdom, E-mail: skb@sanger.ac.uk. Lowell L. Lewis, Government of Montserrat, Brades, Montserrat, E-mail: lowl.lewis@gmail.com. Lionel E. Michael, Environmental Health Division, Ministry of Health and Social Development, Tortola, British Virgin Islands, E-mail: zelmichael@hotmail.com. Maria J. Sanchez, Pan American Health Organization, Washington, DC, E-mail: sanchezmar@paho.org. Reynold Hewitt, One Health Center for Zoonoses and Tropical Veterinary Medicine, Ross University School of Veterinary Medicine, Basseterre, Saint Kitts and Nevis, E-mail: reynoldhewitt@students.rossu.edu.

This is an open-access article distributed under the terms of the Creative Commons Attribution (CC-BY) License, which permits unrestricted use, distribution, and reproduction in any medium, provided the original author and source are credited.

\section{REFERENCES}

1. World Health Organization, 2019. Weekly Epidemiological Record, Vol. 50. Geneva, Switzerland: WHO, 601-612.

2. Ferrer E, Villegas B, Mughini-Gras L, Hernandez D, Jimenez V, Catalano E, Incani RN, 2020. Diagnostic performance of parasitological, immunological and molecular tests for the diagnosis of Schistosoma mansoni infection in a community of low transmission in Venezuela. Acta Trop 204: 105360.

3. Pan American Health Organization, 2014. Schistosomiasis Regional Meeting. Defining a Road Map toward Verification of Elimination of Schistosomiasis Transmission in Latin America and the Caribbean by 2020. Washington, DC: PAHO.

4. Hewitt R, Willingham AL, 2019. Status of schistosomiasis elimination in the Caribbean region. Trop Med Infect Dis 4: 24.

5. Zoni AC, Catalá L, Ault SK, 2016. Schistosomiasis prevalence and intensity of infection in Latin America and the Caribbean countries, 1942-2014: a systematic review in the context of a regional elimination goal. PLoS Negl Trop Dis 10: e0004493.

6. Pointier JP, 2008. Guide to the Freshwater Molluscs of the Lesser Antiles. Hackenheim, Germany: Conch Books, 128.

7. Pointier JP, Jourdane J, 2000. Biological control of the snail hosts of schistosomiasis in areas of low transmission: the example of the Caribbean area. Acta Trop 77: 53-60.
8. Gutiérrez A, Pointier JP, 2005. Guide to the Freshwater Molluscs of Cuba. Hackenheim, Germany: ConchBooks.

9. Prentice MA, 1980. Schistosomiasis and its intermediate hosts in the Lesser Antillean islands of the Caribbean. Bull Pan Am Health Organ 14: 258-268.

10. World Health Organization, 1987. Atlas of the Global Distribution of Schistosomiasis-Dominican Republic, Puerto Rico. Geneva, Switzerland: WHO.

11. Jones SB, 1932. Intestinal bilharziasis in St. Kitts, British West Indies. J Trop Med 35: 129-136.

12. Chitsulo L, Engels D, Montresor A, Savioli L, 2000. The global status of schistosomiasis and its control. Acta Tropica 77: 41-51.

13. Rollinson $D$ et al., 2013. Time to set the agenda for schistosomiasis elimination. Acta Trop 128: 423-440.

14. Tikasingh ES, Wooding CD, Long E, Lee CP, Edwards C, 1982. The presence of Schistosoma mansoni in Montserrat Leeward Islands. J Trop Med Hyg 85: 41-43.

15. Swartz S, Rickards C, 2015. The History of Schistosomiasis in Antigua. Stanford, CA: Stanford University.

16. Druitt T, Kokelaar B, 2002, The Eruption of Soufriere Hills Volcano, Montserrat, from 1995 to 1999, Vol. 21. Geological Society Memoir No. 21. Bath, United Kingdom: The Geological Society Publishing House.

17. Facon B, Pointier JP, Glaubrecht M, Poux C, Jarne $P$, David $P$, 2003. A molecular phylogeography approach to biological invasions of the New World by parthenogenetic thiarid snails. Mol Ecol 12: 3027-3039.

18. Boissier $\mathrm{J}$ et al., 2016. Outbreak of urogenital schistosomiasis in Corsica (France): an epidemiological case study. Lancet Infect Dis 16: 971-979.

19. Schell SC, 1985. Handbook of Trematodes of North America North of Mexico. Moscow, ID: University Press of Idaho, 369.

20. Pan CT, 1958. The general histology and topographic microanatomy of Australorbis glabratus. Bull Mus Comp Zool Harv 119: 237-299.

21. DeJong RJ et al., 2001. Evolutionary relationships and biogeography of Biomphalaria (Gastropoda: Planorbidae) with implications regarding its role as host of the human bloodfluke, Schistosoma mansoni. Mol Biol Evol 18: 2225-2239.

22. Palumbi SR, 1996. Nucleic acids II: the polymerase chain reaction. Hillis DM, Moritz C, Mable BK, eds. Molecular Systematics. Sunderland, MA: Sinauer, 205-248.

23. Kumar S, Stecher G, Tamura K, 2016. MEGA7: molecular evolutionary genetics analysis version 7.0 for bigger datasets. $\mathrm{Mol}$ Biol Evol 33: 1870-1874.

24. Lu L, Zhang SM, Mutuku MW, Mkoji GM, Loker ES, 2016. Relative compatibility of Schistosoma mansoni with Biomphalaria sudanica and $B$. pfeifferi from Kenya as assessed by PCR amplification of the $S$. mansoni ND5 gene in conjunction with traditional methods. Parasit Vectors 9: 166.

25. Alba A, Vazquez AA, Sanchez J, Lounnas M, Pointier JP, HurtrezBousses S, Gourbal B, 2019. Patterns of distribution, population genetics and ecological requirements of field-occurring resistant and susceptible Pseudosuccinea columella snails to Fasciola hepatica in Cuba. Sci Rep 9: 14359.

26. Paraense WL, 2001. The schistosome vectors in the Americas. Mem Inst Oswaldo Cruz 96: 7-16.

27. De Noya BA, Balzan C, Arteaga C, Cesari I, Noya O, 1999. The last fifteen years of schistosomiasis in Venezuela: features and evolution. Mem Inst Oswaldo Cruz 94: 139-146.

28. Floch H, Fauran P, 1954. Essais infructueux d'infection expérimentale de Tropicorbis kuhnianus (Clessin) par Schistosoma mansoni. Bull Soc Pathol Exot 47: 452-459.

29. Paraense WL, 1988. Biomphalaria kuhniana (Clessin, 1883), planorbid mollusc from South America. Mem Inst Oswald Cruz 83: 1-12.

30. Fernandez MA, Thiengo SC, 2010. Susceptibility of Biomphalaria straminea from Peixe Angical dam, Tocantins, Brazil to infection with three strains of Schistosoma mansoni. Mem Inst Oswaldo Cruz 105: 488-491.

31. Scholte RG, Carvalho OS, Malone JB, Utzinger J, Vounatsou P, 2012. Spatial distribution of Biomphalaria spp., the intermediate host snails of Schistosoma mansoni, in Brazil. Geospat Health 6: S95-S101.

32. Nassi H, 1980. Donnes experimentales sur le cycle biologique de Petasiger caribbensis n. sp. (Trematoda: Echinostomatidae) parasite larvaire de Biomphalaria glabrata en Guadeloupe. Ann Parasite Hum Comp 55: 41-55. 
33. World Health Organization, 2009. Elimination of Schistosomiasis from Low-Transmission Areas: Report of a WHO Informal Consultation. Geneva, Switzerland: WHO.

34. Pointier J, Théron A, Borel G, 1993. Ecology of the introduced snail Melanoides tuberculata (Gastropoda; Thiaridae) in relation to Biomphalaria glabrata in the marshy forest area of Guadeloupe, French West Indies. J Molluscan Stud 59: 421-428.

35. Madsen $\mathrm{H}, 1979$. Further laboratory studies on the interspecific competition between Helisoma duryi (Wetherby) and the intermediate hosts of Schistosoma mansoni Sambon: Biomphalaria alexandrina (Ehrenberg) and B. camerunensis (Boettger). Hydrobiologia 66: 181-192.

36. Dobson M, 2004. Replacement of native freshwater snails by the exotic Physa acuta (Gastropoda: Physidae) in southern Mozambique; a possible control mechanism for schistosomiasis. Ann Trop Med Parasit 98: 543-548.

37. Ebbs ET, LokerES, Brant SV, 2018. Phylogeography and genetics of the globally invasive snail Physa acuta Draparnaud 1805, and its potential to serve as an intermediate host to larval digenetic trematodes. BMC Evol Biol 18: 103.

38. Nassi H, 1978. Data on the life cycle of Ribeiroia marini guadeloupensis n. ssp., a trematode sterilizing Biomphalaria glabrata in Guadeloupe. Acta Trop 35: 41-56.

39. Nassi H, Bayssade-Dufour C, 1980. Life cycle of Clinostomum golvani n. sp. (Trematoda: Clinostomidae) a larval parasite of Biomphalaria glabrata, the snail vector of Schistosoma mansoni in Guadeloupe. Ann Parasitol Hum Comp 55: 527-540.
40. Theron A, Coustau C, Rognon A, Gourbière S, Blouin MS, 2008. Effects of laboratory culture on compatibility between snails and schistosomes. Parasitology 135: 1179-1188.

41. Gaspard J, Usey MM, Fredericks-James M, Sanchez-Martin MJ, Atkins L, Campbell CH, Corstjens P, van Dam GJ, Colley DG, Secor WE, 2020. Survey of schistosomiasis in Saint Lucia: evidence for interruption of transmission. Am J Trop Med Hyg 102: 827-831.

42. Mouahid G, Mintsa Nguema R, Al Mashikhi KM, Al Yafae SA, Idris $\mathrm{MA}$, Mone H, 2019. Host-parasite life-histories of the diurnal vs. nocturnal chronotypes of Schistosoma mansoni: adaptive significance. Trop Med Int Health 24: 692-700.

43. Caldeira RL, Jannotti-Passos LK, Dos Santos Carvalho O, 2017. Use of molecular methods for the rapid mass detection of Schistosoma mansoni (Platyhelminthes: Trematoda) in Biomphalaria spp. (Gastropoda: Planorbidae). J Trop Med 2017: 8628971.

44. Sato MO et al., 2018. Usefulness of environmental DNA for detecting Schistosoma mansoni occurrence sites in Madagascar. Int J Infect Dis 76: 130-136.

45. Sengupta ME et al., 2019. Environmental DNA for improved detection and environmental surveillance of schistosomiasis. Proc Natl Acad Sci U S A 116: 8931-8940.

46. Alzaylaee H, Collins RA, Rinaldi G, Shechonge A, Ngatunga B, Morgan ER, Genner MJ, 2020. Schistosoma species detection by environmental DNA assays in African freshwaters. PLoS Negl Trop Dis 14: e0008129. 